care. Major congenital anomaly remains the main cause of death in stillbirths and early neonatal deaths. FGR continues to appear as a significant associated factor with perinatal mortality. Improved antenatal detection is a potentially modifiable factor. As recommended by the Institute of Obstetrics and Gynaecology, second trimester fetal anomaly ultrasound scanning should be universally available for all pregnant women in Ireland. A public health education programme on perinatal deaths and modifiable risk factors should be developed.

\section{P79 THE PREVALENCE AND CORRELATES OF TOBACCO SMOKING IN IRISH UNIVERSITY STUDENTS, FOCUSING ON SOCIAL SMOKING AND SELF-IDENTIFICATION OF SMOKERS; A CROSS-SECTIONAL STUDY}

${ }^{1} \mathrm{C}$ O'Mahony*, ${ }^{2} \mathrm{IJ}$ Perry. ' School of Medicine, University College Cork, Cork, Ireland; ${ }^{2}$ Department of Epidemiology and Public Health, University College Cork, Cork, Ireland

10.1136/jech-2019-SSMabstracts. 230

Background Social smoking is becoming increasingly common, emerging as a separate and distinct pattern of smoking behaviour to regular smoking. Smoking denial, too, has become more prevalent, with those who engage in smoking behaviour often not self-identifying as smokers. This study aims to examine the prevalence of smoking and social smoking in Irish university students and the self-identification of same, along with assessing other factors for any association the may have with smoking behaviour, namely smoking identity, frequency of tobacco consumption and alcohol and drug use.

Methods A cross-sectional study was carried out in the form of a web questionnaire distributed to undergraduate students of University College Cork (UCC). 1,606 initial responses were collected. Exclusion criteria were applied, removing graduate students, those who had incorrectly completed the questionnaire and a small number of duplicates, yielding a final sample size of 1,434 and a final response rate of $10.4 \%$. Data were analysed using IBM SPSS software and the method of analysis included both chi-square testing and multinomial logistic regression analyses.

Results $58.2 \% \quad(\mathrm{n}=834)$ of respondents are smokers with $77.2 \%(n=644)$ of those being social smokers. Social smoking has significant associations with a number of smoking characteristics including decreased frequency of habit $(\mathrm{OR}=0.084$; $95 \% \mathrm{CI}=0.044-0.160 ; p<0.001)$, sourcing tobacco from others $(\mathrm{OR}=2.211 ; 95 \% \quad \mathrm{CI}=1.401-3.489 ; \quad p<0.001)$, less inclination to quit $(\mathrm{OR}=0.426 ; 95 \% \quad \mathrm{CI}=0.231-0.792$; $p=0.007)$ and being influenced to smoke while drinking $(\mathrm{OR}=3.698 ; 95 \% \mathrm{CI}=1.461-9.362 ; p=0.006)$ or if others are smoking $(\mathrm{OR}=3.085 ; 95 \% \mathrm{CI}=1.495-6.365 ; p=0.002)$. While $76.8 \%$ of regular smokers self-identified as smokers, only $12.3 \%$ of social smokers self-identified as smokers $(\mathrm{OR}=0.078,95 \% \quad \mathrm{CI}=0.040-0.153 ; p \leq 0.001)$. Smoking in general is associated with substance use and misuse $(\mathrm{OR}=2.754 ; 95 \% \mathrm{CI}=1.613-4.705 ; p<0.001)$ in comparison to non-smokers.

Conclusion Social smoking is a prevalent behaviour in university students and constitutes the majority of smoking behaviour amongst those surveyed. The difference in results between social smoking and regular smoking groups reinforces that social smoking is a distinct smoking pattern. There is a vast discrepancy in the self-identification of smokers and their smoking behaviour, more so amongst social smokers than regular smokers. Limitations of this study included low response rate and potential for self-selection bias. Further study could be carried out in this area with regards to smoking interventions and potential need to target these groups specifically in public health campaigns.

\section{P80 THE JOINT CONTRIBUTION OF SOCIOECONOMIC CIRCUMSTANCES AND ETHNIC GROUP TO VARIATIONS IN PRETERM BIRTH, NEONATAL MORTALITY AND INFANT MORTALITY IN ENGLAND AND WALES - A POPULATION-BASED RETROSPECTIVE COHORT STUDY USING ROUTINE DATA FROM 2006 TO 2012}

C Opondo*, R Gray, J Hollowell, Y Li, JJ Kurinczuk, MA Quigley. National Perinatal Epidemiology Unit, University of Oxford, Oxford, UK

\subsection{6/jech-2019-SSMabstracts.231}

Background Neonatal and infant mortality rates in England and Wales have declined in recent years. However, disparities in outcomes persist. This study aimed to describe the variation in risks of adverse birth outcomes across ethnic groups and socioeconomic circumstances, and to explore the evidence of mediation by socioeconomic circumstances on the effect of ethnicity on birth outcomes.

Methods The data came from the 4.6 million singleton live births in England and Wales between 2006 and 2012. Socioeconomic circumstances was measured using the Index of Multiple Deprivation (IMD). We estimated the slope and relative indices of inequality to describe differences in birth outcomes across IMD, and the proportion of the variance in birth outcomes across ethnic groups attributable to IMD. We investigated mediation by IMD on birth outcomes across ethnic groups using structural equation modelling.

Results Neonatal mortality, infant mortality and preterm birth risks were $0.2 \%, 0.3 \%$ and $5.6 \%$ respectively. Babies in the most deprived areas had $47 \%$ to $129 \%$ greater risk of adverse birth outcomes than those in the least deprived areas. Minority ethnic babies had $48 \%$ to $138 \%$ greater risk of adverse birth outcomes compared with white British babies. Up to a third of the variance in birth outcomes across ethnic groups was attributable to differences in IMD, and there was strong statistical evidence of an indirect effect through IMD in the effect of ethnicity on birth outcomes.

Conclusion There is evidence that socioeconomic circumstances could be contributing to the differences in birth outcomes across ethnic groups.

\section{P81 THE ASSOCIATION BETWEEN AIR POLLUTION AND ACUTE HOSPITAL ADMISSIONS IN DUBLIN 2007-2016}

${ }^{1} \mathrm{M}$ Robinson*, ${ }^{2} \mathrm{G}$ Kelly, ${ }^{2} \mathrm{E}$ O'Reilly. ${ }^{1}$ Public Health Dept South East, Health Services Executive, Kilkenny, Ireland; ${ }^{2}$ University College Cork, Cork, Ireland

\subsection{6/jech-2019-SSMabstracts.232}

Background Outdoor air pollution has a significant impact on human health and has been declared a 'public health emergency' by the World Health Organisation. An estimated 14,400 years of life are lost annually in Ireland due to 1200 premature deaths caused by air pollution. Cardiovascular disease and stroke are the commonest causes of premature death, followed by respiratory disease. Numerous studies worldwide 
have described the association between air pollution and acute illness, however few studies have been conducted in Ireland to date. This study estimates the association between changes in mean daily air pollutant levels and daily acute hospital admissions in Dublin.

Methods Mean 24-hour levels of fine particulate matter $\left(\mathrm{PM}_{2.5}\right)$, coarse particulate matter $\left(\mathrm{PM}_{10}\right)$, and pollutant gases were calculated for the central Dublin area as a whole, using data from EPA monitors between 2007 and 2016. Daily total acute hospital admissions for respiratory and cardiovascular/cerebrovascular conditions were obtained from Healthcare Pricing Office records, for hospitals within the Dublin area, over the same period. Univariate analyses were performed, to investigate the association between individual pollutants and admissions, followed by analyses that mutually adjusted for several pollutants, with a lag of up to 2 days, to further describe the associations observed. Meteorological variables were controlled for in the model.

Results Univariate analysis revealed carbon monoxide as the strongest predictor of respiratory admissions. Multivariate analysis also identified sulphur dioxide as a strong predictor of respiratory admissions and $\mathrm{PM}_{2.5}$ and nitrogen dioxide as the strongest predictors of cardiovascular admissions.

Conclusion This study describes the extent of the impact of air pollution on hospital admissions and presents models for predicting future admissions with varying levels of pollution. The findings may inform policies to reduce urban air pollution, to develop early warning systems for the public and to improve the preparedness of hospital emergency departments on days of poor air quality.

\section{P82 CRITICAL DISCOURSE ANALYSIS OF THE JOINT COMMITTEE MEETINGS ON THE EIGHTH AMENDMENT OF THE CONSTITUTION OF IRELAND}

IS Shiplo, 1,2K O'Donoghue, 1,3S Meaney*. 'University College Cork, Pregnancy Loss Research Group, Cork, Ireland; ' ${ }^{2}$ niversity College Cork, The Irish Centre for Fetal and Neonatal Translational Research (INFANT), Cork, Ireland; ${ }^{3}$ University College Cork, National Perinatal Epidemiology Centre, Cork, Ireland

\subsection{6/jech-2019-SSMabstracts.233}

Background The 1983 Eighth Amendment to the Irish Constitution stated that the right to life of a pregnant mother and her unborn were equal, which meant that pregnancy terminations were illegal in Ireland. Ongoing debate surrounding strict pregnancy termination laws compelled the Irish government to form a committee tasked with deliberating the arguments for and against repealing the Eighth Amendment as well as forming recommendations. The objective of this study is to evaluate the issues raised and how information was presented during the joint committee meetings on the Eighth Amendment.

Methods Published transcripts from the Joint Committee on the Eighth Amendment of the Constitution meetings were accessed online for analysis. The committee's deliberations commenced on September 20, 2017 and concluded on December 14, 2017. This qualitative study applied a critical discourse analysis, which evaluates language in its social and cultural context. Critical discourse analysis allows for the deconstruction of language to gain an insight and understanding of socially produced meanings, recognising the ability for language to perpetuate inequalities and power dynamics.
Results Seven themes were identified from the meetings' contents related to pregnancy termination: including fatal fetal anomalies, rape and incest, decriminalisation, mental health, human rights, risk and practical issues. Throughout proceedings research evidence was often misrepresented and distorted in order to spin findings in support of members' arguments. Anecdotal evidence, including emotionally-laden narratives, was used to persuade members with divergent views to change their political and ideological opinions about what is socially desirable and acceptable. When discussing the risk and practical issues of introducing termination of pregnancy, the matter of conscientious objection and maternity hospitals whose governance are influenced by religious ethics were debated, clearly illustrating the influence of cultural and religious ideologies over the health of the population.

Conclusion The framing of the discourse throughout the meetings likely influenced the committee members' knowledge, perception, and understanding of key issues, consequently impacting the development of the pregnancy termination legislation introduced in 2019. This study demonstrates that healthcare is influenced by the political context and prevailing religious ideologies in Ireland. This study reveals the potential for underlying bias in political structures to sway healthcare legislation, which can impact health and in particular women's reproductive health.

\section{P84 IS SOCIAL ISOLATION AS BAD FOR HEALTH AS SMOKING 15 CIGARETTES PER DAY? FINDINGS FROM TWO LARGE PROSPECTIVE UK COHORTS}

RW Smith, I Barnes*, G Reeves, J Green, V Beral, S Floud. Nuffield Department of Population Health, University of Oxford, Oxford, UK

\subsection{6/jech-2019-SSMabstracts.234}

Background Social isolation has been associated with increased mortality, and a much-cited previous review stated that the risk is comparable to smoking 15 cigarettes per day. However, the available evidence is inconsistent. We examined social isolation in relation to all-cause mortality in two UK prospective cohorts, and assessed whether the excess risk associated with social isolation was comparable to that for smoking 15 cigarettes per day.

Methods After excluding people with vascular disease, cancer or low self-rated health, to minimise reverse causation bias, 326,169 Million Women Study (MWS) participants (mean age $=68$ years) and 296,913 UK Biobank (UKB) participants (mean age $=56$ years), were followed for death. Social isolation was measured using an index of self-reported frequency of contact with family or friends, social group contact, and living alone. Adjusted RRs for all-cause mortality were calculated using Cox regression, comparing most isolated participants to the least isolated. Analyses adjusted for smoking and 12 other possible confounding factors.

Results Within each cohort, about 12\% of participants were classified as most isolated and $44 \%$ as least isolated. Over 5.9 years of follow-up, 9667 MWS participants died; the most isolated had about a $30 \%$ excess risk of all-cause mortality compared to the least isolated $(R R=1.28,1.19-1.38)$. Over 6.8 years follow-up, 4694 UKB participants died; the most isolated had about a $40 \%$ excess risk of mortality compared to the least isolated $(R R=1.38,1.27-1.51)$. Of the constituent measures contributing to isolation, living alone was most 